\title{
Internal Deliberation Defending Climate-Harmful Behavior
}

\author{
Maria Wolrath Söderberg ${ }^{1}$ (D) $\cdot$ Nina Wormbs $^{2}$ (D)
}

Accepted: 17 November 2021 / Published online: 4 February 2022

(c) The Author(s) 2022

\begin{abstract}
Most people in countries with the highest climate impact per capita are well aware of the climate crisis and do not deny the science. They worry about climate and have climate engaged attitudes. Still, their greenhouse-gas emissions are often high. How can we understand acting contrary to our knowledge? A simple answer is that we do not want to give up on benefits or compromise our quality of life. However, it is painful to live with discrepancies between knowledge and action. To be able to avoid taking the consequences of our knowledge, we deal with the gap by motivating to ourselves that the action is still acceptable. In this article, we use topical analysis to examine such processes of motivation by looking at the internal deliberation of 399 climate engaged people's accounts of their reasoning when acting against their own knowledge. We found that these topical processes can be described in at least four different ways which we call rationalization, legitimization, justification and imploration. By focusing on topoi we can make visible how individual forms of reasoning interact with culturally developed values, habits and assumptions in creating enthymemes. We believe that these insights can contribute to understanding the conditions for climate transition communication.
\end{abstract}

Keywords Knowledge behavior gap $\cdot$ Rhetoric $\cdot$ Topoi $\cdot$ Climate change $\cdot$ Internal deliberation · Legitimize

\section{Introduction}

Plato did not distinguish between knowledge and morality but saw knowing as inextricably linked to action. For long, researchers, politicians and officials have acted as if Plato was right: if we develop and communicate climate knowledge,

Maria Wolrath Söderberg

maria.wolrath-soderberg@sh.se

Nina Wormbs

nina@kth.se

1 Rhetoric, Södertörn University, Stockholm, Sweden

2 History of Technology, KTH Royal Institute of Technology, Stockholm, Sweden 
people will learn and act accordingly. When they do not act wisely, we assume a lack of knowledge and try to communicate research findings more and better. The last decade, however, researchers have found that this approach risks leaving those skeptical to climate change even more stubborn in their resistance at the same time as the efforts are wasted on those already informed but still not acting (Moser \& Dilling 2007). For argumentation scholars, it is no surprise that one persuasive strategy does not fit all.

Climate skepticism is a serious obstacle to progress and has been given much attention both in public debate and by researchers in the field (Jylhä 2017; Poortinga et al. 2011). In this article, we instead focus on the fact that many both know and confess to sustainability ideals, but still do not act accordingly (Kollmuss \& Agyeman 2002). In Sweden, where our study was conducted, and in large parts of the world including the U.S., citizens are rather well informed about issues related to climate change and a vast majority have positive attitudes to climate effort (Leiserowitz et al. 2013; Marlon et al. 2016; Solevid 2017). However, this attitude does not seem to reflect in how they act.

A large proportion of the population in affluent countries exhibit this gap. Wealthy people generally have high emissions. This means that they thus have large amounts of emissions to cut, without losing a decent lifestyle. Moreover, their lifestyles presumably form ideals for people less affluent.

In our study we focus on people who not only are aware of and worried about the crisis, they even describe themselves as climate engaged, but still make choices that harm the climate. We assume that they are closer to behavioral change than those who are indifferent to, or deny, climate change and therefore an essential group to understand.

We, humans, do not like to act against what we believe since we want to identify ourselves as consistent wholes. Internal conflicts, often conceptualized as cognitive dissonances with the term coined by Festinger (1957), can be very painful. We tend to make great efforts to either practice what we preach or rationalize our behavior so that it is compatible with our knowledge, values, and desired identity, and moreover, that can be supported by arguments considered valid in our culture. Combining perspectives from Rhetoric and Climate Knowledge Dissemination Studies, the focus of this article is to analyze such internal processes. An overarching purpose is to better understand the conditions for climate communication.

In this study we reached out to climate engaged groups and individuals and asked if they had experienced a situation when they acted against their own knowledge regarding climate change. If so, they were asked to fill in a survey where they accounted for their reasoning. We received 399 complete answers. In those answers, we looked for topoi of a specific kind - strategies of meaning making - motivating a climate harmful behavior. In the present analysis, we hypothesize that when values or habits are challenged, people try to defend them by invoking perspectives and arguments congruent to their choices. This article is based on the idea that at least some of the inertia blocking behavioral transformation could be understood (and potentially also addressed) by looking at the rationalization processes people use to avoid the consequences of their knowledge. 
The term rationalize is, however, as we have seen in our analysis, too narrow for our purpose, and we will offer more precise terms. We also challenge the idea that this dissonance is best described as cognitive.

In this study, we look for topoi which help us resist living as we know we ought to. We argue that these topoi need to be discerned, made visible, articulated, understood and problematized, in order to be possible to address in climate communication. First, we summarize relevant research. Then we present our study and understanding of topical theory. Thereafter we look at our material and discuss how the topoi found can be understood.

\section{Rhetorical Reading of Explanatory Models of Inertia in Climate Change}

The rhetorical theory of topoi is rooted in pre-socratic traditions, but it was further developed and refined by Aristotle as a system for understanding and navigating complex and value laden political problems (Aristotle, On Rhetoric; Vico 2018; Wolrath Söderberg 2017, 2019). The climate crisis might be the most challenging such problem of our time.

\subsection{Topical and Rhetorical Approaches}

The theory of topoi, has been used to understand the climate debate also in earlier research (Cox 1982; Farrell \& Goodnight 1981; Ross 2013). Ross (2017) uses a topical analysis to understand how controversies emerge and are maintained or exploited in the crossroads between different stakeholders. One theme is the topos of uncertainty, used by both environmentalists and corporations in the fracking debate (Kerr 2017). This relates to how scientific controversy is manufactured in order to postpone regulation and stimulate status quo (Ceccarelli 2011; Oreskes \& Conway 2010), and how environmentalists stress risks (Walker and Walsh, 2012). Walsh and Boyle explored topology as techniques for socially engaged post critical rhetoric (2017). Other current topical studies focus on how scientific models are understood and used in climate communication (Walsh and Prelli 2017), and by climate change sceptics and how such strategies can be coped with by scientists (Walsh 2017).

The discursive interaction between science, the public and politics in relation to environmental issues has gained attention by rhetorical scholars from the perspective of other close notions, such as analogy (Dryzek and Lo 2015). It has also attracted interest in other related fields, such as literary and media studies (Cantrill and Oravec 1996; Nisbet 2009; Schneider and Nocke 2014) and in argumentation studies (for instance Rodrigues et al 2019).

Congenerous to our research is a study in psychology which addresses how rhetorical framing affects the tendency to go from knowledge to action (Morton et al. 2011). Recently, Lamb et al. published an interdisciplinary study on climate action delay which presents a typology of discourses such as redirecting responsibility, pushing non transformative solutions and surrender (2020). 
All of these works focus on the interaction between individuals or different stakeholders. In this article, we primarily address another discourse, namely the internal one. We are interested in the inertia among people who have the knowledge but still act in ways that they know harm the climate. All our respondents are climate engaged and confess to a sustainable life style. The conflict is thus "within" them.

Perelman and Olbrects Tyteca call this internal discourse"deliberation intime" (1969). The idea is grounded in the notion that thinking about problematic issues can be understood as an internal dialogue, an approach recognized already in Aristotle (Topics; On Rhetoric) and explored by philosophers like Vico (2018), rhetoricians like Mendelson (2013), and social psychologists, like Billig (1996). This is not an entirely individualistic perspective since topoi entail culturally negotiated conceptual structures. The idea is that topoi are at play in our"internal deliberation" and by studying such topoi we can get hold of some of the features of our thinking, and at the same time of our culture. We do not claim that this internal deliberation can fully explain the inertia in the transition, but we argue that it plays a role. There are, however, additional explanatory models.

\subsection{Literature on the Climate Knowledge-Behavior Gap}

The question of why we do not act according to our knowledge (or our intention) has been addressed in relation to sustainability issues from many perspectives. The most influential article is probably by Kollmuss and Agyeman who developed a conceptual model of the parameters promoting and hindering environmental action, departing from earlier research (2002). They distinguish between internal and external factors. Internal factors are such as motivation, knowledge and values, a complex called 'pro-environmental consciousness'. This interacts with external factors, which are demographic (gender, age, education, etc.), infrastructural, economic, social and cultural. Among the listed barriers, old behavior patterns are the most prominent. Others are lack of knowledge and emotional blocking of such new knowledge, values preventing learning and lack of internal incentives (Kollmuss \& Agyeman 2002).

Another influential approach by the psychologist Robert Gifford suggests 29 psychological barriers that limit climate change mitigation and adaptation, which he calls "dragons of inaction". He sorts them in seven categories: limited cognition, ideologies, comparisons with others, sunk costs, discredence, perceived risks and limited behavior (Gifford 2011). Some of these barriers are more discernable than others in the choice of arguments, such as social comparison, perceived inequity or tokenism (which is when actions with little or no impact on greenhouse gas emissions becomes an alibi for higher cost but more effective actions).

The knowledge-behavior gap has also been studied within several other disciplines, for example geography (Blake 1999), business (Young et al. 2010), psychology (Markowitz and Shariff 2012) sociology (Kennedy et al. 2009), and ethics, from the viewpoint of akrasia, the weakness of the will, by for instance Kretz who suggest a moral education to overcome the gap (2012). Specifically relevant to our study is the work of the sociologist Norgaard, which builds on interviews with Norwegians, 
one of the most environmentally minded people in the world, but with a large footprint due to the wealth created by the petroleum economy (2011). Norgaard uses a model of socially organized denial. This term does not refer to a rejection of facts, but a failure to transform the acknowledgement of facts into social action. An important insight in Norgaard's work is that culture works on action by shaping a repertoire or tool kit, providing"chunks of culture" such as symbols, stories, rituals and world-views that can be used in different combinations to legitimize action and nonaction. This conception is familiar to rhetoricians. The repertoire could be understood as doxa and the tools as topoi (Wolrath Söderberg 2017).

Much of the present research dealing with the inertia of climate mitigation is developed in regard to the value-laden, multi-faceted and intangible nature of the issue. Psychologists focus on the evolutionarily developed tendency to prioritize the urgent and the tangible as a strong psychological barrier for dealing with more long term or distanced threats (Gifford 2014; Stoknes 2015). That fear paired with impotency can explain inertia is also a popular hypothesis (Moser \& Dilling 2007; O’Neill \& Nicholson-Cole 2009).

Another influential strand of explanation has to do with a perceived irrationality of the human cognition. This is often related to critique of the so-called information deficit model (Barr \& Gilg 2007; Bulkeley 2000). We might believe that we change our behavior when we are faced with facts urging us to think in new directions. But it is difficult when our habits are deeply rooted in our values, identity or ideology. From a rhetorical perspective, the narrow definition of rationality applied here, could be questioned.

New approaches in social psychology, like the politically motivated reasoning paradigm developed by Kahan, entail a re-evaluation of rationality (2015). For an individual, it can have greater and more tangible consequences to act out of line with the group than making factual mistakes (Hornsey et al. 2016; Luo \& Zhao 2019). We believe that rhetorical studies can contribute by joining these seemingly disparate perspectives in a more encompassing conceptual frame.

\section{The Theory: Internal Deliberation, Topoi and Enthymeme}

Perelman and Olbrechts-Tyteca noted, inspired by Aristotle, that rhetoric is not about logical inferences but about justifying our beliefs or actions (1969). At least in regard to multifaceted issues, we do not necessarily start with evidence and then deduce our conclusions from them. Instead, we often set out from our beliefs in search for topoi that can help us find convincing arguments. This model applies to deliberations with others, but also to our discussions with ourselves (Billig 1996). However, we are not autonomous in this. To be convincing to ourselves, the arguments must be socially accepted by a relevant audience, they must be acknowledged as doxa. Topoi are such modes of reasoning that have a good track record in our social context (Wolrath Söderberg 2012). They are values, facts, argumentation schemes or modes of reasoning shared by people and therefore likely to be accepted. 
Topoi can thus be used as instructions on how to design an argument (Rubinelli 2017, Walton 1996).

A useful concept in this regard is the enthymeme (Aristotle, On Rhetoric). To convince someone, it is not enough with good arguments - an enthymeme must occur. Topoi are forms of reasoning that tend to produce enthymemes. The enthymeme is a notoriously disputed concept. Here it is understood as the event when the argument becomes meaningful to the discussion partner (according to the understanding in Wolrath Söderberg 2010, 2017 and in Conley 2008). But not just for logical or factual reasons; the argument must be related to things that the co-discussant already knows and considers important. The argument must be compatible with the experienced identity and social context of the discussion partner. In order to lead to action, it must also invoke the feelings and aspirations of the discussion partner (Mc Burney 1936, Miller \& Bee 1972). Then an enthymeme may occur, which means that the message catches on, or forms a connection with the discussion partner's existing experience of meaning and works convincingly (Conley 1984). It is thus rather a process of coherence, identification and engagement than of logical inference (Wolrath Söderberg 2010). ${ }^{1}$ Topoi are thus forms of reasoning with a propensity to produce the perceived audience's recognition, engagement and assent.

When we talk about internal deliberation in this context, we must imagine that this enthymemic process takes place in a dialogue of self-convincing. The enthymeme occurs when one can motivate one's actions to oneself in a meaningful way and without too much annoying dissonance.

In this study we are interested in how enthymemes are created and what topoi are at play when people deal with inconsistences between their beliefs and actions in climate issues. By looking closer at the arguments they use, we can discern a variety of recurring topoi and distinguish common underlying assumptions and thought structures in a group or population regarding a specific issue. The topoi used by individuals can speak to how meaning is formed collectively. This meaning making is equally interesting regardless to what degree the argument was successful in bridging the cognitive dissonance; it still teaches us about possible thought structures relating to climate change action in this group of people.

This is important as there is reason to believe that the human inclination to attend to the dissonance with the help of justifications is an important factor in maintaining inertia in climate matters. Experiencing dissonance can be a moral engine, and a motivational factor for change. When the crack becomes visible or too large, it is too painful to refrain from acting. Several studies show that making people aware of the dissonance between their climate knowledge/attitude on the one hand and actions on the other is potentially compelling, given that other ways of thinking or being are offered, compatible with doxa (Dickerson et al. 1992; Dickinson et al. 2013; Osbaldiston \& Schott 2011; Thøgersen 2004).

\footnotetext{
1 This is thus a broader understanding of topical meaning making than in kindred modern theories about argumentation schemes which mainly focuses on logical or semantic features (see Rubinelli 2009, Walton, Reed \& Macagno 2008).
} 


\section{A Mixed Method: Survey and Extraction of Topoi}

This interdisciplinary study applies a methodological approach that differs from what is common in the discipline of Rhetoric, namely the analysis of already existing artefacts. Instead it is based on a generated material-a survey which was circulated on social media, in climate groups and on webpages between March 13th and 28th of April, 2019. It was distributed with the following description: "Are you committed to climate change? Have you still sometimes acted against your own better knowledge? Tell us what it concerned and how you reasoned!".

The survey contained 16 questions. After the respondents approved data collection according to GDPR, we asked whether a sustainable lifestyle was important to them, whether they considered themselves to have knowledge of the climate crisis and whether they sometimes behaved in ways that they knew were harmful. The 399 respondents that answered affirmatively to these questions were included in our analysis. We asked the respondents to tell us about a situation when the climate harmful behavior took place, why they thought they made the choice, if they were aware of the conflict when it happened and if they motivated the choice for themselves. The key question was: "What arguments did you use? How did you convince yourself that it was okay?" The responses to this last question constitute the material for our analysis.

The sample is not representative of the population but is a self-recruited group. We assume that our survey attracted the attention of people who were aware of, and perhaps already more or less frustrated, by the gap between their beliefs and action. Our target group was those who also retroactively could identify with the cognitive dissonance. Moreover, we were not interested in representativity, nor did we have any statistical aspirations.

We applied an inductive "bottom up" approach, reading the responses and looking for recurrent topoi of a specific kind-motivating a climate harming behavior. We had no prior coding scheme, ${ }^{2}$ but we specifically looked for strategies of meaning making - ways of dealing with the gap between knowledge and behaviourpotentially producing enthymemes. The found topoi were given names and were clustered and grouped, eventually forming a coding scheme with a dozen types of topoi. The responses were often rich and elaborated and we could often discern two or even more topos in each response. Wolrath Söderberg did the first coding and then both of us went through the material together, which led to some modifications in the coding.

Looking closer at the different topoi, scrutinizing them from likeness and differences in how they called for a possible adherence or assent of audiences and thus produced enthymemes, some overarching principles of meaning making emerged. In order to describe this, a conceptual frame with four categories was developed. This process of analysis corresponds well to the method of phenomenograhy in

\footnotetext{
${ }^{2}$ It cannot, however, be ruled out that Wolrath Söderberg's, who did the first coding, familiarity with different systems of topoi influenced the discernment (such as the works Aristotle, Perelman \& Olbrechts Tyteca 1969, Walton, Reed \& Macagno 2008 and Kienpointner 1992).
} 
pedagogical research where the aim is to find a repertoire of qualitatively different ways of experiencing or thinking about something that is in turn grouped and classified inductively from likeness and difference. Such a set of categories capturing the variation of reasoning in regard to a phenomenon is called an outcome space (Marton, 1986). ${ }^{3}$

\section{A Conceptual Frame}

Now, we will anticipate our results and present a conceptual frame inductively derived from our analysis. We found that reasoning dealing with dissonance regarding climate behavior operates in different ways. We could discern four major ways of meaning making, which we call rationalization, legitimization, justification and imploration. Sometimes these different terms can be used to describe the workings of the same topos. Sometimes these terms are interchangeable, but they represent four different perspectives on how topoi invoke meaning by calling for a perceived audience's adherence.

Rationalization refers to how the argument is used to make a behavior logical or coherent with thoughts, attitudes or general life style of the user. One seeks support in one's "logic", patterns of understanding or one's identity. It is a reasoning of consistency or coherence. Perelman and Olbrecht-Tyteca uses the term quasi-logical to describe these kinds of topoi (1969).

Legitimization is when the argument is used as a defense against critique. All topoi are more or less legitimizing, but here we save the term legitimization for argumentation belonging to the legal sphere in a broad understanding, genus judiciale in rhetorical terms. A legitimization is about the distribution of guilt. Often this is done by seeking support from rules or principles, by redefining or reducing the magnitude of the"crime" or by blaming it on someone else. Many possible topoi of this kind have been described in the teaching of stasis with roots from Hermagoras and later Hermogenes and others (Nadeau 1959, Kienpointner 1997).

Justification, refers to how the argument is used to claim that a choice is morally acceptable. One seeks support from shared values. In internal deliberation this is the perceived audience's moral assent. Justification is kindred to legitimization in that it downplays the severity of the "deed", but seeks support in another manner.

Imploration, finally, is when arguments are used to ask for understanding, compassion or forgiveness. It is related to apologia,"the speech of self-defence"(Ware \& Linkugel 1973), which is also found in the teaching of stasis (Cicero, De Inventione). But all the above-mentioned processes can be used apologetically. Here we mean appeals to pity or generosity. This is often done by admitting the misconduct and calling for identification. This is also related to the concept of deprecatio in stasis theory (Cicero, De Inventione). But while deprecatio stresses the down-playing

\footnotetext{
3 Our topical analysis marries a phenomenographical method with a rhetorical approach. Instead of interviews, the material is surveys. It focuses on argumentative structures. Thus, we take seriously the intermediate role of linguistic choices, which are often otherwise missed in phenomenography.
} 
of one-self, we wanted a term pointing at the call for mercy by invoking pity or empathy. This is a humanitarian discourse.

In order to avoid confusion, we do not call these four ways of meaning making topoi, but use the notion for the structures found behind the arguments in the material. They can, however, also be seen as topoi but of a more general kind.

\section{Analysis and Results}

The most common topoi used to motivate climate harmful behavior in our study are sorted by headings corresponding to more general thinking structures. ${ }^{4}$ Under each such heading, different topoi are presented in the form of a quote of a representative example. Each topos is exemplified with more quotes and comments. After each such section, we analyze the findings from a more comprehensive perspective.

\subsection{Account or Budget Thinking}

This is the most prevalent type of topos in the material, having to do with husbandry in one way or another.

\section{"I make many other good choices".}

This topos counts less climate-damaging habits as savings, creating space in the climate account. Withdrawals, in the form of climate harmful activities, can then be made from this account. What is"measured" is often the difference between present and previous habits:'I change my diet towards more vegetables, think about reducing business trips (using video conferencing instead), shop very little, recycle most of what I can, sort my garbage etc." But it can also be in relation to a perceived budget:"I still do a lot that is good-for example, bicycle to work." The budget may also be set up in relation to other people's (imagined) habits or ideas about what is normal:"Comparatively, I am not as guilty as some other individuals in society". In the examples above, the currency is apparently emissions in one form or another, but sometimes the currency is time:"I make very conscious environmental choices in my everyday life, which is most of the year." In this example, a distinction is also made between everyday life and exceptions. The former compensates for the latter.

"I am doing a lot for the climate, so I can treat myself with...."

As mentioned, the currency on the perceived account deposit or budget is often greenhouse gas that could have been emitted but was not. Sometimes, however, the currency is instead efforts benefitting the climate in other ways:'I am self-sufficient in vegetables and eggs". Also a future investment can be counted:"I plan to get solar panels." Efforts in the professional role are common:”My research hopefully

\footnotetext{
4 These headings, organizing more general thinking structures, could of course also be call topoi, but we spare the notion to the more specific modes of reasoning, presented in the form of quotes.
} 
contributes to a better world." Working with antibiotic resistance or solar energy, or with politics, can be regarded as offsetting. One informant says:'I am one of the last to be indebted. In general, I think that those who are knowledgeable and are working actively towards climate change should be given greater freedom in making climate-damaging choices. It is the sum per individual that counts." Some justify their climate-damaging action with their more general climate attitude:'I am still on plus with all my climate commitment." An account-topoi that stands out converts the reasoning:"To be able to make other climate smart choices". What appears to be climate-damaging is, in fact, an investment that can add to the climate account:'I go by car in order to get energy and time to make other climate-smart choices" or "If I recover well (from my weariness), I will have the power to influence companies and policies to make major changes and stop most of the private flying" (as an argument for flying on vacations).

\section{"I've been ill for a long time".}

In a few cases, we see another type of account thinking that has more to do with compensation. The respondents describe their climate-harmful behavior as rewards for efforts:'I've worked hard and cut down on consumption for much of my life and 'treat' myself with an air trip now". It could also be a compensation for suffering:'I lived so 'righteously' before and I have so much pain in my body" (as an argument for flying on vacation). The balancing of the climate against the"inner environment" is interesting. Someone says:'Making life easier for me and my family creates inner peace and less stress. In a way, an 'internal' environmental issue." The currency in this topos does not have to be suffering, it can also be positive experiences:'The joy it gives me outweighs the collective cost." This type of topos is akin to the topos that has to do with goal conflicts.

\subsubsection{Understanding the Account and Budget Topoi}

As long as we breathe and eat, it is impossible to totally avoid affecting the climate. It is therefore sensible to compare different actions and try to balance them into a reasonable whole. Conceptually, we can distinguish between account and budget thinking, but in practice the boundary is often fuzzy in our material. In account thinking, you can economize with your climate impact as with financial means, make transactions or even earn on your account. Budget thinking on the other hand combines the commonplace"less (emissions) is better than more" with an idea of an imagined climate-economic space. This space is often extracted from a comparison; it can be with earlier habits, other people with higher emissions or what is considered normal (in a local context). The space can also be related to an idea of a right to emit a certain amount or to what is perceived as fair in regard to an (un-articulated) idea about (global) equity. Budget-thinking structures open for the moral dimensions of the issue more clearly than account thinking. The currency in both regards can be to abstain from something or reduce consumption, but it can also be a change of direction in a longer perspective or thriftiness as a trait of character. The currency can be climate work or other contributions to a sustainable society, but it can also be 
pure engagement in climate issues, having a hard work or a stressing everyday life or sufferings having to do with completely other dimensions in life.

These topoi create enthymemes primarily by rationalization. There is a basic economic structure behind all these topoi. It produces a kind of mathematical thinking structure which is quite resistant to counter arguments due to its perceived cogency. It leaves no crack and thus induces no need for self-reflection, at least if one accepts the thinking structure itself. On the other hand, as reservations and quotes in the material testify, quite a few of the respondents actually show signs of a meta-perspective and in one form or other reveal doubt using this thinking structure. Sometimes the account thinking is related to a perceived fair share, either due to some unarticulated right, but sometimes, as it seems, related to equity. In both cases a kind of legitimization is going on.

Even though these modes of reasoning in many ways seem completely sound, they are often applied in problematic ways. For instance, there is a flagrant lack of insight into proportions, partly in terms of the size of different emissions when compared to each other (i. e. when believing that recycling can compensate for long flights), and partly in terms of what is considered normal or fair from a global perspective. The yardstick (the budget space) is often un-reflected and extracted from the perceived normality, which in turn is structured by habits, by the desirable and/ or by the local.

Another problem is called the negative footprint illusion (Gorissen \& Weijters 2016; Sörqvist \& Langeborg 2019), when we count less bad solutions as a plus on the account and assume that we can then later make withdrawals. Here the climate effect is seen as an average of the consumed goods, rather than as a sum. With this logic, it is better for the climate to buy seven T-shirts in eco-material than one in a non-ecological material, but it is a fallacy that it is possible to compensate for large emissions with smaller emissions.

Finally, actions that are bad for climate are often supposed to outweigh actions that are good from other sustainability perspectives. Veganism can, for example, to some extent be compared with emissions from transport in regard to climate impact, but when crediting one's account with other things such as work against antibiotic or one's own fatigue, it becomes obvious that the balancing is more about safeguarding identity than about actually arriving at a reasonable decision (Hope et al. 2018). Furthermore, although account and budget thinking can result in a more climate conscious behavior (Wolrath Söderberg \& Wormbs 2019), we see many examples where savings in one direction seem to allow more extravagance in another. This has been noted in earlier studies and is called"the rebound effect" with a term borrow from Jevons (Gifford 2011; Jevons 1865). Account and budget thinking help us prioritize our actions, but combined with ignorance they also generate cognitive delusions and appeasing arguments for the one in need to rationalize passivity.

\subsection{Relativization}

Another common type of topos in the material are different kinds of relativization. It can be topoi which relativize the problem, which relativize the user of the topos 
(or the collective to which the user belongs), or which situates the blame at another level.

\section{"I settled with a journey to Europe instead of NY."}

In this topos the comparison is between what I could have chosen and what I in fact chose. An example is"'The car runs on biogas and is therefore not'super harmful'." The topos suggests a negotiation of the size of the crime, that you were not that bad or that it could have been worse.

"What does it matter on the whole?"

Benoit calls this minimization (1995). The topos is found behind arguments that justify the act with its insignificance in relation to a larger whole. An expression that is common in slightly different variants is:"A drop in the sea". However, the action is often related to other people:"What does my little act matter, when other people totally give a darn". Often, the action is related to an indeterminate"all","everyone" or"others", but sometimes it is related to a"majority" or to"people." Those people are in one way or another worse. However, there are a number of arguments that place the informants' own climate-harmful choices in relation to a more general level of society.

"The choice of the individual is negligible. The issue must be resolved at a higher political level."

Several informants motivate their climate-damaging choices by referring the responsibility to another level. It can be the political:"The responsibility for the transition from fossil fuels, meat and overconsumption lies not only with the citizen. Industry has more responsibility and above all politics." Some informants want to see more control from above. A few emphasize the responsibility of the business sector:'It is quite unfair that the blame is placed on us consumers and that global warming is seen as the result of our poor choices, and not because of the companies that are actually releasing the emissions." Or"Why should I when business and companies do so little." In the latter argument, the lack of exemplarity is being addressed.

\subsubsection{Understanding the Relativization Topoi}

We understand ourselves in relation to our context, which means that it is perfectly normal to reason by relativizing one's own choices. There is great ingenuity with which these comparisons are made. All three types of relativization topoi in this material typically create enthymemes by legitimizations, recognized from the juridical sphere where the magnitude of the "crime" is reduced or transferred. Within account and budget thinking, no crime is committed, or at least it is not seen as a crime. But here, the action is admitted as a problem, and thus downplayed or moved. In the first case, to downplay the problem makes it unimportant. In the second case, compared to all others, it is pickaninny. And in the last case there is a displacement of responsibility to a system level. In the first two cases there is a crack between knowledge and behavior, but the minimization removes the need for behavioral 
change. In the last case the potential crack is immediately mended, and no selfreflection or behavioral change is needed.

The two first types of topoi of relativization also have traces of rationalization; the minimization of the problem or of the self, entails a possibility to dismiss the responsibility based on calculation, to make it microscopic and thus negligible. This is intriguing as we tend to reason otherwise in other areas of life, such as voting, where every vote counts.

The last type of topoi, which displaces the responsibility, incorporates a potential dichotomy. In the public debate the individual level is often set against the systemic. Sometimes it is claimed that a focus on individual change could be counterproductive to the necessary societal change, since it would take attention away from system change and possibly raise tension between groups (Azar 2009).

This contra positioning of the individual and the system level is problematic. Not only because the system is built up by individuals and because individuals can influence the system, but mainly because individuals in dialogue with each other build up the groups and social movements that are engines of system change (Chenoweth \& Stephan 2011; Wolf \& Moser 2011). Most of the responses in this category however neither dichotomize nor use the counter productivity topos, but refer to the injustice in having to take responsibility when guilt should be placed elsewhere. Some evidently se the individual and system level as complementary.

\subsection{Other Values}

A common type of topos is reasoning by highlighting a goal conflict and then making a trade-off where other values than the climate are found to weigh heavier.'The positive consequences outweigh the climate consequences" as one of the informants expresses it.

\section{"I thought it was important to travel abroad in order to understand other cul-} tures."

Climate change is often set against something beneficial to the individual. One example is"I traveled to Bangladesh. It was a once-in-a-lifetime opportunity to go to a wedding there, with my friends."

\section{"I valued the benefits for myself and my family higher than the climate in this particular case."}

Sometimes it is not self-benefit that is emphasized, but rather outcomes that have to do with loved ones. Arguments that have to do with family, children and friends occur in several forms and one form regards the higher value. Sometimes it is very explicit, but usually the conflict does not need to be articulated; it can be presupposed:"My journey is about seeing loved ones." If the journey has this aim, it should not be questioned. Others express the conflict in more vigorous dichotomic manner:'With some things I do not compromise. The family is most important. If I have to choose between taking a train and being with the family, I choose the family." 
Most of the arguments in this category have to do with journeys and transports. Often when family is mentioned the argument has to do with time, time with family or children or with practical circumstances. We will look closer at these kinds of arguments in the next category, circumstances.

\subsubsection{Understanding the Topoi Departing from Other Values}

Climate transition entails many goal conflicts. It is often difficult to reduce the impact on climate without sacrifices. And of course, it is painful to give up cherished habits and values. The topoi in this section motivate climate harming actions by emphasizing the goal conflicts.

One could argue that this is a topos that does not fit into a study that deals with acting against one's better knowledge. The respondents have weighed goals against each other, and made peace with a particular action. The dissonance should arguably be gone. However, we argue that the dissonance often remains, and is made bearable by balancing it with other good purposes. This interpretation is supported by the context of the survey, which is clearly about perceived conflicts between knowledge and action. The respondents also state awareness of the conflict at the time of action. Even if we can assume that time might have added some reflection, the respondents report arguments used to motivate the actions to themselves. Some respondents also express a self-critical perspective. It would thus be a mistake to reduce it to discrete event of rational pro- et con reasoning or a finite conclusion from conflicting hierarchies of values. We will elaborate on this interpretation later on in the discussion section.

In this study we set out from the assumption that the internal deliberation is oriented socially, towards more or less consciously imagined audiences. From that perspective this type of topoi create enthymemes mainly by justification. One choses arguments with the potential to get assent by a perceived audience through calling for common values such as the importance of caring for one's family. Examples of imploration are also visible, such as calls for recognition and identification, emotional commitment and pleads for empathy.

Albert Bandura, uses the term selective moral disengagement to describe investing ecologically harmful practices with worthy purposes. It enables people to pursue practices released from the restraint of self-censure. When many reason in a similar way, it reproduces socially accepted behavior. Together all these small choices maintain entire systems of climate-damaging practices (Bandura 2007).

\subsection{Limiting Contexts and Social Considerations}

One type of topos deals with frameworks and conditions limiting our perceived agency and allows us to place responsibility elsewhere. It may be external circumstances like nature or society, but it can also be personal circumstances, like finances, personal problems and health. Many responses demonstrate that we do not act in a vacuum but in interaction with others.

"Either flying or no journey at all." 
A common topos, especially in regard to the most frequent situations mentioned in the survey namely air travel or other transport, is that it is practically impossible to act differently. It may be that it is too expensive, that it takes too long or that there are simply no alternatives. Sometimes it appears as an objective description of reality-it is extremely difficult to get across the Atlantic without flying and we know it is often more expensive to go by train. Sometimes the argument is more about what is either practical or too complicated and often combined with the needs of the family. External circumstance such as an employer or a job demanding travelling is another reason:"I motivated flying [...] with it happening within the framework of my work, which shifted the responsibility to someone else." All these topoi are based in external factors. They are often beyond our control, we cannot do anything about the fact that bus traffic is bad or the flight cheaper than the train. However, it is not a given that one does not have any choices at all. Sometimes a kind of metonymization happens; that the phenomenon is beyond our control, is presented as me having no choice (hypothetically, it might be possible to forgo the trip or pay more for it). It also involves placing responsibility outside one self. But it is also possible to refer to more personal circumstances.

\section{"I have more important bills to prioritize."}

Among the more personal circumstances some of them are closely related to the mentioned themes price and time, but the perspective is different. The argument is not that an alternative choice is too expensive but that the respondent is unable to afford it. The argument is not that the alternative takes more time, but that the informant lacks time, because his or her own life is stressful. Appeals for empathy are also found in another type of topos which also deals with one's own circumstances, namely health:"I have had fatigue depression" (clothing purchases) or"My body aches" (air travel).

"I want to make life easier for my family." We found references to the family among the topoi emphasizing competing values. They are also found here, but rather as conditions or limitations. The family is sometimes referred to as something outside of one self, which entails limitation and needs, for example that you have to pick up the children before a certain time. But more often the family or children are referred to as something you are responsible for:'It won't work with the bus. It takes too much time and the children might have a breakdown" or"I have to have a car with space for my old mother." Often it is a matter of local transport. This category of topoi displays concrete examples with a clear appeal for empathy. For those who have experienced it, it is easy to identify with the fear of children's breakdown on the bus.

\section{"Family peace was more important."}

Attention to the expectations of others also plays a role:"I don't want to disappoint my sister on what she would think would be "political' grounds" or"One must make sacrifices in a relationship even if it goes against one's own beliefs." There can be negotiations with relatives:"I have to compromise with my partner, 
who wants this (trip)" or a specific reference to the social atmosphere:"I'm not ready to.... alienate myself from the group of people I spend time with and work with."

\subsubsection{Understanding the Topoi of Limiting Contexts and Social Considerations}

There are two types of topoi in this section. In one the circumstances are described as imperative. These"I have no choice"- arguments create enthymemes by legitimization. When using topoi referring to external circumstances there is no need for dissonance (at that particular time). Responsibility has effectively been removed from the self. Neither is there any need for critical self-reflection. On the other hand, the respondents choose to mention this as an example of a situation where they acted against what they knew was best. We interpret it as objections to an imagined criticism from others rather than as a response to their own self-reflection.

The other type of topoi, stressing the personal circumstances, appeals for recognition of a need or value such as functioning everyday life (justification) and sometimes also for recognition of exhausting situations or empathy (imploration).

Relatives and employers are mentioned most often when motivating climate harming actions with arguments related to the social context. When referring to family and employers, it is clear that the enthymeme-producing process takes place mainly through justification. One seeks acceptance from shared values like the importance of family life. But there are also dimensions of legitimization, i. e. to move or share the guilt to or with other family members, with whom you have to compromise or avoid disappointing. There are also imploration in the sense that one seeks support in the potential listener's experience of having been sandwiched between one's own moral and the will of others.

In this type of argumentation, the dissonance is present and recognized. In some cases, it is described as a typical goal conflict, where one value clearly triumphs over the other. But in several cases, there seems to be a potential opening for reconsideration.

\subsection{The Human Condition}

Some arguments have to do with being human, simply put. They refer to the imperfection of human beings but also to ambitions and aspirations that sometimes are existential.

\section{"I didn't have the energy."}

"It was easier" and"I needed it to cope" are examples of imperfection. Others refrain from stating arguments, but instead analyze themselves:"Convenience, need to get away and rest, etc. took over." There are also many examples that emphasize one's own drives"I desired",'I wanted." Often, there is a self-critical tone in the analysis"I haven't been thoughtful enough" or even self-denigration"Because I'm a bit stupid." Many state"laziness" as a cause of the climate-damaging act."It is human to err" also capture the topoi. 


\section{"It dampened anxiety at the moment."}

More specific needs are also mentioned that may refer to internet surfing or food consumption. Some express that a difficult circumstance gives them a right:'I've had a veritable shit-year, gone on crutches for 8 months, so I'm worth it." Or they see it as a more general right:"One must have the right to treat oneself". It can also be a reward:"I was worth it because of the intense and successful work this week."

"I have cut back on flying in recent years."

Many respondents use arguments from direction:"After all, I fly much less than last year". The behavioral change and the ambition are put forward as mitigating circumstances. Related to ambition is intention. Sometimes the purpose of the individual behavior is described as noble. In this example it is contrasted with other purposes that are not as morally justified:"My trip is about seeing loved ones, not flying to holiday destinations for pure pleasure."

\section{"I rarely fly and will opt it out in the future."}

A cognate topos is that of rarity:'As long as I don't do it more than typically once a month, it won't do more harm" (impulse buying clothes) or'I don't travel far more than once a year."The latter is a kind of minimization (as brought up among topoi of relativization), but it is also an argument of exception, which has dimensions of morality and identity. Another example is:'I convinced myself by thinking that it was only this time, and that I will improve." A common argument is that it was a special occasion:'I can travel less later, but my children are only young once". It might also be"the last time I do it."

\subsubsection{Understanding the Topoi Referring to the Human Condition}

At first glance, these topoi seem to be of two types, of weakness and of hedonism. But looking closer there is more to it. As indicated, in comparison with the other types of topoi, there is more often a clear meta-perspective in the answers, or even a self-critical tone. One could assume that this self-reflective perspective would coincide with a greater tendency to actually change behavior. However, comparing how the answers co-varied with the responses to a later question in our survey, which reads"Would you act the same way today?", we found no support for that. In fact, the proportion of those who would do the same again was slightly higher in this group. The argument repaired the crack between the action and the self-image, but the remorse was temporary. This suggests that the confession works a letter of indulgence that allows the action to happen again.

The arguments in this category all have traits of justification, creating enthymemes by appealing to common experiences, as being tired or having the right to recover, or being imperfect. It is often combined with imploration. In the more selfcritical examples where the informant describes him- or herself as weak and in more or less subtle ways makes an apology, the dissonance is displayed naked. Rather than fixing the crack, one appeals for understanding, sometimes also with self-irony 
and jokes and in a few cases by wallowing in self-humiliation, expecting to invoke a comforting response.

Intention matters. It is obvious in the material that climate behavior is not all about the climate but also about who you are. Trying, having ambitions, and to decrease from a previous high level, can be highlighted as conciliatory. These are arguments safe-guarding the perceived identity. The topoi do not deny the action, nor the effect of it. They rather say that I am a good person even though I did this: because I want to do good, I try and besides, you cannot be perfect. These kinds of topoi are disconnected from scales and quantities and the comparison is with one self. At the same time the topoi say: don't judge me! It is a justification by reasserting: I still adhere to the same moral standards as you. But there is also legitimization: the magnitude of the action is reduced by its rarity and the intention to decrease. Rationalization occurs in the form of dissociation from the action so that the individual can still be coherent with the perceived self.

The dissonance is visible and recognized. There is a more or less conscious struggle between the perceived identity and action. In some cases, the respondent is clearly distancing the self from the action which opens for self-reflection, but in some other cases one can suspect that the self-scourging works as a substitute for behavioral change.

\section{Discussion}

To investigate internal deliberation with the aim of finding topoi that can shed light on the knowledge-behavior gap is a new approach with potential to contribute to the ongoing research on climate change communication. We started by interpreting the respondents' deliberation as an internalized dialogue in which the arguments are structured with respect to their power to convince a (more or less consciously) imagined environment. ${ }^{5}$ We didn't see it just a silent dialogue with themselves but also with non-present others. Even though we asked people who recognized that they performed this inner conflict, it is an important finding that it does exist and lends itself to analysis. This also means that the internal deliberation has the potential to change if the collective discourse changes.

However, we can also discern"a third voice" in many of the responses. We note that many responses are self-reflective, as if the informants see themselves from the outside and enter a discussion between their less and more conscious self. This could be an opening for negotiation and transformation, but sometimes it might also be an alibi for avoiding real change. Moreover, many respondents use several arguments, aligned with different topoi, not necessarily pointing in the same direction.

The analysis of the topoi we have found reveal that many, which belong to the two larger groups, concerning budget or account and relativization respectively, build on misunderstandings and misconceptions. Some simply have the facts wrong or tend

\footnotetext{
${ }^{5}$ It is impossible for us to know how the responses were affected by the fact that there actually was a real audience, namely us researchers.
} 
to perspectivize in a way that is questionable. This is also apparent in the perceived understanding of the relation between individual behavior and systemic change. This is an important insight as it can affect the focus of climate-change communication.

Research on nudging has revealed that it is important that acting correctly is made easy (Thaler \& Sunstein 2012). Our respondents testify to this. Furthermore, the family and close significant others are central in everyday choices. Finally, the role of identity is central. Great effort can be put into protecting one's own self-understanding.

Perelman and Olbrecht-Tyteca state that informal argumentation is about seeking the real or perceived audience's adherence. This is relevant in relation to the ways in which our respondents create enthymemes overcoming their dissonance or at least safeguarding their peace of mind. In internal deliberation however, the audience is the self, but the reasoning is measured against the perceived doxa. ${ }^{6}$ In our study, adherence is sought in four major different ways: through rationalization where the behavior is made consistent within a generally accepted thinking structure (a logical discourse), through legitimization where the behavior is made acceptable in regard to common principles of responsibility and distribution of guilt (a legal discourse), through justification where the behavior is made reasonable in relation to generally shared values (a moral discourse), and through imploration where the behavior is made human and recognizable (a humanitarian discourse). Even though these four are analytically different processes, it is also clear that they are partly overlapping perspectives.

For instance, a bit surprising, it seems that rationalization is a highly moral process. It is deeply threatening to the moral identity and self-image to exhibit logical cracks. In fact, all four processes are fundamentally moral in that they are about upholding self-respect and safeguarding the conscience.

In a similar way it can be said that all four processes are about rationalization, i.e. based on creating or maintaining consistency or coherence. Legitimization is about establishing or maintaining the link between the action and the principles that we adhere to, i.e. the principles for when it is reasonable or not to blame someone. Justification is about clarifying the connection between the action and what the environment perceives as important values. And imploration is about reminding of the connection between you and me as human beings.

All four are also about common values. The arguments are useless unless a potential audience accepts the underlying topoi as reasonable. And all four, not just imploration, are about empathy, in that the topoi must have the potential to create recognition in the imagined audience.

There is potential for broader application of the conceptual frame. It might be useful for understanding inertia in behavioral changes even in relation to other goal conflicts, such as those related to health, politics or morality.

\footnotetext{
${ }^{6}$ Perelman and Olbrechts-Tyteca coined the concept universal audience, which could be applicable here. However, since we do not need it to make our point and since it's meaning is so contested, we refrain from using it.
} 
We have done a topical study, which is an analytical approach that is well suited to capture meaning-making in regard to goal conflicts. This is not surprising based on a rhetorical tradition, but we find it interesting that the inductive method points in a slightly different direction than the Aristotelian teaching of topoi (and thus also Perelman and Olbrechts-Tyteca's theory). Aristotle distinguishes between idia, which is more content-dependent reasoning, and more general topoi, where he primarily devotes effort to his 28 topoi enthymematon. These enthymeme inducing topoi have different characters. Some are figure-like, for example to reason based on analogy (no. 16). Others are more like premises, such as assuming that what people claim in front of others is not always what they consider to be true in private (no. 15), and still others are more about reversing a discussion, such as accusing or defending based on mistakes that have been made (no. 27).

Wolrath Söderberg has previously launched an interpretation of Aristotle's topoi as discursive habits that within a certain argumentative practice are preferred and considered valid. Topoi can then be discussion points, i. e. the nodes for the dispute in a conversation. It can be warrants, assumptions on which the claim depend. It can also be discursive operations, that is, argumentative strategies to assert something. Aristotle's topoi enthymematon are the latter, according to this understanding (See Wolrath Söderberg, 2017 for a more thorough argumentation). The topoi we have presented in this article can on the one hand be described as discursive operations of the same type as Aristotle's topoi enthymematon. Some of them are quite general, just as Aristotle described them, i. e. the comparison with others and the focus on competing values, which are very similar to topoi found in Aristotle's list. But what the analysis shows is that such discursive operations can also be very content specific-such as the account- and budget thinking and the specific traits of the comparison. This stands in contrast to the often made division between specific and general topoi in the discourse, a division that furthermore often is assumed to be connected to material and form. This in turn is an assumption that Thomas Conley claims is an anachronistic hylomorphism (Conley 1978). On the other hand, and confirming the problem of dissociating material and form, all of the topoi found are also based on assumptions that warrant the claim. For instance, account thinking is based on ideas about sizes and proportions of emission, comparison is based on ideas on who to compare with and on normality, and dichotomizing the individual and the system is based on assumptions on how the different levels of society connect (or not connect).

Another finding that rather confirms the Aristotelian idea about topoi is the indivisible union of rational, emotional and moral dimensions in many examples of the respondents' reasoning and also that meaning making in goal conflicts is complex and multi-faceted. This is an important contribution to theory about the knowledgeaction gap.

Research on the knowledge-action gap has a general tendency to regard knowledge and attitudes as something you either have or have not (discrete, with a mathematical term), and to see behavioral change in the same way, as something that either happens (momentaneously) or not (which might be explained by the focus on skepticism or when knowledge is denied). Rhetorical studies have for long had a much more complex understanding acknowledging emotions, trust and values, that 
competing perspectives exist and that change takes time. The internal dialogue has many voices and it can contain contradictions.

It should also be noted that even though it is possible to divide the identified topoi in relation to how successful they are in overcoming the dissonance, that would not serve our purpose. We were first and foremost looking for the meaning making regarding climate change inaction and believe that even though the internal deliberation is aimed at working with the dissonance, the framing of the survey and the responses illustrate that there is still room for complex reflection with the respondents. Our approach affords human action and argument that is not just logical but also includes self-criticism, doubt and perhaps even regret. The arguments used by our respondents do not preclude a remaining ambivalence with their own action. In fact, we believe that this was a reason for them to respond in the first place given the framing of the survey. The findings might even suggest that it is a mistake to assume that making a considered choice and coming out with the best solution or the least bad removes the urge of compelling knowledge or the voice of the conscience. People seem to have the capacity to house conflicting reasons and values. ${ }^{7}$

These findings challenge our departure, viewing internal deliberation as dialogical. Rather, we see a polylogue as described by Lewiński and Aakhus (2014). The term polylogue describes deliberations or discussions that include not only many voices but also many logics and positions. Lewiński and Aakhus believe that it is difficult to do justice to the multidimensional nature of such interactions if they are seen solely as a pro-con-deliberations, as a struggle between values or at all through purely dyadic analysis. Aakhus and Lewiński also state that by highlighting positions, relationships and places (in the sense of spaces or venues) one can see and describe a more complex dynamic in polylogue (Aakhus \& Lewiński 2017). This theory is developed in regard to complex debates with many participators. Applied on our material it becomes clear how voices and standpoints constituting the inner negotiation constantly respond to impulses that have to do with relationships, moral positions, situations and places. That the polylogue is a central characteristic of moral reflection has also been pointed out in dialogue ethics, for instance by Martin Buber (Buber 2013).

Aakhus and Lewiński do not engage with the temporal dimension. The kind of deliberation that we see in our informants' responses is not completed when the decision is made or even when the action is performed. To many it seems to be an ongoing or rather recurrent, slowly developing negotiation where old and new topoi appear and disappear, depending on the persons situation, dialogue partners and a doxa under constant transformation.

\footnotetext{
7 This is also obvious in another study within the same research project which shows that climate transition is a complex internal deliberation where more self-interested motives or driving forces in the social context compete with insights into one's own emissions and the acuteness of the climate crisis, responsibility for future generations, impulses from role-models and a supporting social network. This takes time (Wormbs \& Wolrath Söderberg, 2021).
} 


\section{Conclusion}

An understanding of individual meaning making as absolute implies that if one does not change behavior in the face of new knowledge one is either incapable of learning or irrational. If we, on the other hand, believe that a human being is capable of many perspectives, values, impulses, experiences and feelings, that complexity is important to understand as the different pieces making up a person constantly change. In our study, this complexity is visible in the internal deliberations and brought forward in our analysis. The different topoi give us key information on the perspectives, driving forces and motives that act as hindrances in a transition to a sustainable society and are important for climate-change communication. Our study relates to psychological studies of barriers, but the focus on the arguments is a key difference. The rhetorical perspective allows for an analysis of the linguistic choices that carry thought structures and culturally developed positions. It further underscores the importance of the existential and deeply human dimension of the internal deliberation, the struggle between contradicting views and values, the juxtaposition of conflicting ambitions and convictions, living in a social context. This is an ongoing human practice, but one that is often neglected in the public discourse on climate change were the media logic promotes extreme static positions rather than nuanced reasoning. In this study we can see that the dissonance is not a purely cognitive phenomenon, at least not in the general sense of cognitive. Yes, it is a dissonance, a threatening crack, a squeak, but it has many other dimensions than the cognitive, such as emotions, identity, morality, collective values and probably also a basic fear of not being accepted in the group. Thus, the dissonance is not accessible for transformation if it is handled as solely cognitive. The responses in our survey is a testament to that.

The gist of our survey is that part of the inertia of the climate transition can be explained by the respondents having access to rhetorical resources to develop sufficiently coherent answers to the critical questions they expect in their social context. This suggests that it may be meaningful to make such resources less viable, for example by problematizing them in the general discourse. This also corresponds to the mentioned studies on how interventions intended to increase the experience of cognitive dissonance can lead to behavioral changes (Dickerson et al. 1992; Osbaldiston \& Schott 2011). But there is reason to think that it should be done with sensitivity and empathy because such a support seems to be central to people who have actually changed their behavior because of concern for climate change (Wormbs \& Wolrath Söderberg 2021).

Author Contributions Both authors made substantial contributions to the design of the study; to the acquisition and interpretation of data and to the theoretical discussion and synthesis. However from different conceptual perspectives.

Funding Open access funding provided by Södertörn University. This work was supported by Riksbankens jubileumsfond under Grant P18-0402:1: Understanding justification of climate change non-action. 
Availability of Data and Material Work is ongoing to make survey responses available through Södertörn University, Stockholm. Presently data are available from the corresponding author, upon request.

\section{Declarations}

Conflicts of interest There are no conflicts of interest.

Open Access This article is licensed under a Creative Commons Attribution 4.0 International License, which permits use, sharing, adaptation, distribution and reproduction in any medium or format, as long as you give appropriate credit to the original author(s) and the source, provide a link to the Creative Commons licence, and indicate if changes were made. The images or other third party material in this article are included in the article's Creative Commons licence, unless indicated otherwise in a credit line to the material. If material is not included in the article's Creative Commons licence and your intended use is not permitted by statutory regulation or exceeds the permitted use, you will need to obtain permission directly from the copyright holder. To view a copy of this licence, visit http://creativecommons.org/licen ses/by/4.0/.

\section{References}

Aakhus, M., \& Lewiński, M. (2017). Advancing Polylogical Analysis of Large-Scale Argumentation: Disagreement Management in the Fracking Controversy. Argumentation 31(1) 179: 207

Aristotle. (1991). On Rhetoric: A Theory of Civic Discourse. Oxford University Press.

Aristotle. (2015). Topics. Aeterna Press.

Azar, C. (2009). Makten över klimatet [The Power Over Climate]. Bonnier pocket.

Bandura, A. 2007. Impeding ecological sustainability through selective moral disengagement. International Journal of Innovation and Sustainable Development 2 (1): 8.

Barr, S., and A.W. Gilg. 2007. A conceptual framework for understanding and analyzing attitudes towards environmental behaviour. Geografiska Annaler: Series B, Human Geography 89 (4): 361-379.

Benoit, W. L. (1995). Accounts, excuses, and apologies: a theory of image restoration strategies. State University of New York Press.

Billig, M. 1996. Arguing and thinking: a rhetorical approach to social psychology. Cambridge University Press.

Blake, J. 1999. Overcoming the 'value-action gap' in environmental policy. Local Environment 4 (3): 257-278.

Buber, M. 2013. I and Thou. Bloomsbury Academic.

Bulkeley, H. 2000. Common knowledge? Public understanding of climate change in Newcastle Australia. Public Understanding of Science 9 (3): 313-333.

Cantrill, J. G., \& Oravec, C. (1996). The symbolic earth: discourse and our creation of the environment. University Press of Kentucky.

Ceccarelli, L. 2011. Manufactured scientific controversy: science, rhetoric, and public debate. Rhetoric \&amp; Public Affairs 14 (2): 195-228.

Chenoweth, E., and M.J. Stephan. 2011. Why civil resistance works: the strategic logic of nonviolent conflict. Columbia University Press.

Cicero, M.T. 2006. De inventione. Harvard University Press.

Conley, T.M. 1984. The enthymeme in perspective. Quarterly Journal of Speech 70 (2): 168-187.

Conley, T.M. 1978. "Logical hylomorphism" and Aristotle's koinoi topoi. Central States Speech Journal 29 (2): 92-97.

Cox, J.R. 1982. The die is cast: Topical and ontological dimensions of the locus of the irreparable. Quarterly Journal of Speech 68 (3): 227-239.

Dickerson, C.A., R. Thibodeau, E. Aronson, and D. Miller. 1992. Using cognitive dissonance to encourage water conservation. Journal of Applied Social Psychology 22 (11): 841-854. 
Dickinson, J.E., D. Robbins, V. Filimonau, A. Hares, and M. Mika. 2013. Awareness of tourism impacts on climate change and the implications for travel practice. Journal of Travel Research 52 (4): 506-519.

Dryzek, J.S., and A.Y. Lo. 2015. Reason and rhetoric in climate communication. Environmental Politics 24 (1): 1-16.

Farrell, T.B., and G.T. Goodnight. 1981. Accidental rhetoric: the root metaphors of three mile Island. Communication Monographs 48 (4): 271-300.

Festinger, L. 1957. A theory of cognitive dissonance. Stanford University Press.

Gifford, R. 2011. The dragons of inaction: Psychological barriers that limit climate change mitigation and adaptation. The American Psychologist 66 (4): 290-302.

Gifford, R. (2014). Environmental psychology: principles and practice. Optimal Books.

Gorissen, K., and B. Weijters. 2016. The negative footprint illusion: perceptual bias in sustainable food consumption. Journal of Environmental Psychology 45: 50-65.

Hope, A.L.B., C.R. Jones, T.L. Webb, M.T. Watson, and D. Kaklamanou. 2018. The role of compensatory beliefs in rationalizing environmentally detrimental behaviors. Environment and Behavior 50 (4): 401-425.

Hornsey, M.J., E.A. Harris, P.G. Bain, and K.S. Fielding. 2016. Meta-analyses of the determinants and outcomes of belief in climate change. Nature Climate Change 6 (6): 622-626.

Jevons, W.S. 1865. The coal question: an inquiry concerning the progress of the nation, and the probable exhaustion of our coal-mines. Macmillan.

Jylhä, K.M. 2017. Denial versus reality of climate change. In Encyclopedia of the anthropocene, ed. D.A. DellaSalla and M.I. Goldstein, 487-492. Elsevier.

Kahan, D.M. 2015. The politically motivated reasoning paradigm, Part 1: what politically motivated reasoning is and how to measure it. In Emerging trends in the social and behavioral sciences, ed. S.M. Kosslyn, 1-16. Wiley.

Kennedy, E. H., Beckley, T. M., McFarlane, B. L., \& Nadeau, S. (2009). Why we don't" walk the talk": Understanding the environmental values/behaviour gap in Canada. Human ecology review, 151-160.

Kerr, J. 2017. Designing doubt: the tactical use of uncertainty in hydraulic fracturing debates. In Topic-driven environmental rhetoric, ed. D.G. Ross. Routledge.

Kienpointner, M. 1992. Alltagslogik. Frommannholzboog.

Kienpointner, M. 1997. On the art of finding arguments: what ancient and modern masters of invention have to tell us about the "Ars Inveniendi." Argumentation 11 (2): 225-236.

Kollmuss, A., and J. Agyeman. 2002. Mind the Gap: Why do people act environmentally and what are the barriers to pro-environmental behavior? Environmental Education Research 8 (3): 239-260.

Kretz, L. 2012. Climate change: bridging the theory-action gap. Ethics and the Environment 17 (2): 9-27.

Lamb, W.F., G. Mattioli, S. Levi, J.T. Roberts, S. Capstick, F. Creutzig, J.C. Minx, F. Müller-Hansen, T. Culhane, and J.K. Steinberger. 2020. Discourses of climate delay. Global Sustainability.

Leiserowitz, A., Maibach, E. W., Roser-Renouf, C., Feinberg, G., \& Howe, P. (2013). Climate change in the american mind (SSRN Scholarly Paper ID 2298705)

Lewiński, M., and M. Aakhus. 2014. Argumentative polylogues in a dialectical framework: a methodological inquiry. Argumentation 28 (1): 161-185.

Luo, Y., and J. Zhao. 2019. Motivated attention in climate change perception and action. Frontiers in Psychology.

Markowitz, E.M., and A.F. Shariff. 2012. Climate change and moral judgement. Nature Climate Change 2 (4): 243-247.

Marlon, J., Howe, P., Mildenberg, M., \& Leiserowitz, A. (2016). Yale climate opinion maps-U.S. 2016 [Map]. Yale program on climate change communication.

Marton, F. 1986. Phenomenography — a research approach to investigating different understandings of reality. Journal of Thought 21 (3): 28-49.

McBurney, J.H. 1936. The place of the enthymeme in rhetorical theory. Speech Monographs 3 (1): 49-74.

Mendelson, M. (2013). Many sides: a protagorean approach to the theory, practice and pedagogy of argument. Springer Science \& Business Media.

Miller, A.B., and J.D. Bee. 1972. Enthymemes: body and soul. Philosophy \&amp; Rhetoric 5 (4): 201-214.

Morton, T.A., A. Rabinovich, D. Marshall, and P. Bretschneider. 2011. The future that may (or may not) come: How framing changes responses to uncertainty in climate change communications. Global Environmental Change 21 (1): 103-109.

Moser, S.C., and L. Dilling. 2007. Creating a climate for change: communicating climate change and facilitating social change. Cambridge University Press. 
Nadeau, R. 1959. Classical systems of stases in Greek: hermagoras to hermogenes. Greek, Roman and Byzantine Studies 2: 53-71.

Nisbet, M.C. 2009. Communicating climate change: why frames matter for public engagement. Environment: Science and Policy for Sustainable Development 51 (2): 12-23.

Norgaard, K.M. 2011. Living in denial: climate change, emotions, and everyday life. MIT Press.

O'Neill, S., and S. Nicholson-Cole. 2009. "Fear won't do it": promoting positive engagement with climate change through visual and iconic representations. Science Communication 30 (3): 355-379.

Oreskes, N., \& Conway, E. M. (2010). Merchants of doubt: how a handful of scientists obscured the truth on issues from tobacco smoke to global warming. Bloomsbury Publishing USA.

Osbaldiston, R., and J.P. Schott. 2011. Environmental sustainability and behavioral science: meta-analysis of proenvironmental behavior experiments. Environment and Behavior. 44: 257-299.

Perelman, C., \& Olbrechts-Tyteca, L. (1969). The new rhetoric: a treatise on argumentation. University of Notre Dame Pess.

Poortinga, W., A. Spence, L. Whitmarsh, S. Capstick, and N.F. Pidgeon. 2011. Uncertain climate: An investigation into public scepticism about anthropogenic climate change. Global Environmental Change 21 (3): 1015-1024.

Rodrigues, S., M. Lewiński, and M.A. Üzelgün. 2019. Environmental manifestoes: argumentative strategies in the Ecomodernist Manifesto. Journal of Argumentation in Context 8 (1): 12-39.

Ross, D.G. 2013. Common topics and commonplaces of environmental rhetoric. Written Communication 30 (1): $91-131$

Ross, D.G. 2017. Topic-driven environmental rhetoric. Routledge.

Rubinelli, S. 2017. Aristotle's Topoi and Idia as a map of discourse. In Topologies as techniques for a postcritical rhetoric, ed. L. Walsh and C. Boyle, 17-30. Springer International Publishing.

Rubinelli, S. (2009). Ars Topica: the classical technique of constructing arguments from Aristotle to Cicero. Springer Science \& Business Media.

Schneider, B., and T. Nocke. 2014. Image politics of climate change: visualizations, imaginations. Documentations: Transcript Verlag.

Solevid, M. (2017). Svensk samhällsoro [SOM-presentation]. SOM-Institutet.

Sörqvist, P., and L. Langeborg. 2019. Why people harm the environment although they try to treat it well. Frontiers in Psychology.

Stoknes, P. E. (2015). What we think about when we try not to think about global warming: toward a new psychology of Climate Action. Chelsea Green Publishing.

Thaler, R. H., and Sunstein C.E. 2012. Nudge: improving decisions about health, wealth and happiness. Penguin UK.

Thøgersen, J. 2004. A cognitive dissonance interpretation of consistencies and inconsistencies in environmentally responsible behavior. Journal of Environmental Psychology 24 (1): 93-103.

Vico, G. 2018. On the study methods of our time. Cornell University Press.

Walker, K., and L. Walsh. 2012. "No one yet knows what the ultimate consequences may be": how rachel carson transformed scientific uncertainty into a site for public participation in silent spring. Journal of Business and Technical Communication 26 (1): 3-34.

Walsh, L. (2017). Understanding the rhetoric of climate science debates. Wiley Interdisciplinary Reviews: Climate Change, 8(3), n/a-n.

Walsh, L., and C. Boyle. 2017. Topologies as techniques for a post-critical rhetoric. Springer.

Walsh, L., \& Prelli, L. J. (2017). Getting down in the weeds to get a god's-eye view: the synoptic topology of early American ecology. In Topologies as techniques for a post-critical rhetoric (pp. 197-218). Palgrave Macmillan, Cham.

Walton, D. 1996. Argumentation schemes for presumptive reasoning. Erlbaum.

Walton, D., C. Reed, and F. Macagno. 2008. Argumentation schemes. Cambridge University Press.

Ware, B.L., and W.A. Linkugel. 1973. They spoke in defense of themselves: on the generic criticism of apologia. Quarterly Journal of Speech 59 (3): 273-283.

Wolf, J., and S.C. Moser. 2011. Individual understandings, perceptions, and engagement with climate change: Insights from in-depth studies across the world. Wires Climate Change 2 (4): 547-569.

Wolrath Söderberg, M. 2010. Aristoteles enthymem [Aristotle's Enthymeme]. Rhetorica Scandinavica 53: 36-66.

Wolrath Söderberg, M. 2012. Topos som meningsskapare: retorikens topiska perspektiv på tänkande och lärande genom argumentation [Topoi as meaning makers: thinking and learning through argumentation - a rhetorical perspective]. Retorikförlaget. 
Wolrath Söderberg, M. (2017). Aristoteles retoriska toposlära - en verktygsrepertoar för fronesis [Aristotle's Rhetorical Teaching of Topoi - a Phronetical Toolbox]. Södertörn Rhetorical Studies.

Wolrath Söderberg, M., \& Wormbs, N. (2019). Grounded: beyond flygskam. Fores.

Wormbs, N., and M.W. Söderberg. 2021. Knowledge, fear, and conscience: reasons to stop flying because of climate change. Urban Planning 6 (2): 314-324.

Young, W., K. Hwang, S. McDonald, and C.J. Oates. 2010. Sustainable consumption: green consumer behaviour when purchasing products. Sustainable Development 18 (1): 20-31.

Publisher's Note Springer Nature remains neutral with regard to jurisdictional claims in published maps and institutional affiliations. 